\title{
Thermal Properties and Structural Features of Multilayer Films Based on Chitosan and Anionic Polysaccharides
}

\author{
Galina N. Gubanova ${ }^{1}$, Valentina A. Petrova ${ }^{1}$, Svetlana V. Kononova ${ }^{1}{ }^{\mathbb{D}}$, Elena N. Popova ${ }^{1}$, \\ Valentina E. Smirnova ${ }^{1}$, Alexander N. Bugrov ${ }^{1,2}$, Vera V. Klechkovskaya ${ }^{3}$ and Yury A. Skorik ${ }^{1, * \mathbb{D}}$ \\ 1 Institute of Macromolecular Compounds of the Russian Academy of Sciences, Bolshoi pr. VO 31, \\ 199004 St. Petersburg, Russia; gubanovagn@yandex.ru (G.N.G.); valentina_petrova_49@mail.ru (V.A.P.); \\ svetlanavkononova@gmail.com (S.V.K.); popovaen@hq.macro.ru (E.N.P.); ves@hq.macro.ru (V.E.S.); \\ bugrov.an@mail.ru (A.N.B.) \\ 2 Department of Physical Chemistry, Saint Petersburg Electrotechnical University "LETI", ul. Professora \\ Popova 5, 197376 St. Petersburg, Russia \\ 3 Federal Scientific Research Centre "Crystallography and Photonics", Shubnikov Institute of Crystallography, \\ Russian Academy of Sciences, Leninskiy pr. 59, 119333 Moscow, Russia; klechvv@crys.ras.ru \\ * Correspondence: yury_skorik@mail.ru
}

\section{check for} updates

Citation: Gubanova, G.N.; Petrova V.A.; Kononova, S.V.; Popova, E.N.; Smirnova, V.E.; Bugrov, A.N.; Klechkovskaya, V.V.; Skorik, Y.A. Thermal Properties and Structural Features of Multilayer Films Based on Chitosan and Anionic

Polysaccharides. Biomolecules 2021, 11, 762. https://doi.org/10.3390/ biom 11050762

Academic Editor: Pietro Matricardi

Received: 14 April 2021

Accepted: 14 May 2021

Published: 19 May 2021

Publisher's Note: MDPI stays neutral with regard to jurisdictional claims in published maps and institutional affiliations.

Copyright: (c) 2021 by the authors. Licensee MDPI, Basel, Switzerland. This article is an open access article distributed under the terms and conditions of the Creative Commons Attribution (CC BY) license (https:// creativecommons.org/licenses/by/ $4.0 /)$.

\begin{abstract}
This study investigates the thermal and structural properties of multilayer composites based on chitosan (CS) and polyanions with different functionalities, including sodium sulfoethyl cellulose (SEC), sodium alginate (ALG), and sodium hyaluronate (HA). Unlike polyelectrolyte complexes (PECs) obtained by polymer mixing, the formation of a PEC layer by a process of layer-by-layer deposition of oppositely charged polymers is accompanied by the transformation of the CS polymorphic state, and this affects the relaxation and thermal properties of the resulting multilayer composite. X-ray diffraction analysis showed that the formation of the PEC layer in the CS/SEC multilayer film is accompanied by crystallization of the CS chains and the formation of a predominantly anhydrous CS modification. Thermogravimetric analysis of the CS/SEC film registers a high-temperature peak associated with the thermal decomposition of crystalline CS in the PEC composition. According to the dynamic mechanical analysis, the CS/SEC composite was characterized by a single glass transition temperature, indicating a strong interaction between the layers when using SEC (a strong acid salt) as the counterion to CS. For multilayer composites with weak polyacid salts (ALG and HA), the crystallization of CS in the PEC layer is weaker, as reflected in the thermal degradation of these films. A high-temperature peak is recorded in the thermal decomposition of CS/HA and is absent in the case of CS/ALG. Dynamic mechanical analysis of the CS/ALG composite showed two glass transition temperatures close to those of the original polymers, indicating weak PEC formation. The CS/HA composite showed an intermediate response. Thus, the effect of the PEC layer on the properties of the poly-layer composites decreases in the order CS/SEC > CS/HA > CS/ALG.
\end{abstract}

Keywords: chitosan; polyelectrolyte complex; sulfoethyl cellulose; alginic acid; hyaluronic acid; thermal analysis; dynamical mechanical analysis

\section{Introduction}

Chitosan (CS) possesses unique biological and physicochemical properties that make its polyelectrolyte complexes (PECs) highly useful in medicine, in the pharmaceutical and food industries, and in membrane technologies [1-3]. Polyelectrolyte membranes can be manufactured by various techniques (e.g., preparation of a film from the solution containing polyelectrolyte mixture, immersion of a polyelectrolyte film into solution of another polyelectrolyte, etc.). However, the most efficient technique for the preparation of pervaporation membranes is the layer-by-layer deposition of polyelectrolytes [4].

In our previous work, we described a direct method developed to study the structure of thin polymer layers in multilayer composite films, with particular emphasis on the 
structure of the PEC layer in a CS/sulfoethyl cellulose (SEC) composite [5]. We found that the electrostatic interactions occurring during PEC formation led to appearance of "sites" in the polymer network that initiated crystallization of CS within the PEC layer, as evidenced by the appearance of a reflection in the diffractograms at $2 \theta$ about $15^{\circ}$. A similar reflection appeared during the hydrothermal treatment of a CS film, and this was interpreted as the transformation of a hydrated polymorphic modification into an anhydrous polymorph [6].

Our previous investigations have explored the properties of multilayer composites based on combinations of CS with various polyanions, such as sulfoethyl cellulose, sodium alginate (ALG), sodium hyaluronate (HA), and carrageenan (CAR), that vary in their functionalities and structures [7]. For all of the studied polymer pairs, the formation of PEC at the phase interface was accompanied to varying degrees by a transformation of the CS structure from an amorphous hydrated form into a crystalline anhydrous polymorph. The degree of transformation of CS into an anhydrous polymorph depends on the steric availability, amount, and basicity/acidity of the oppositely charged ionic groups that form the PEC sites. Scanning electron microscopy and energy-dispersive microanalysis further disclosed the elemental composition and layer thicknesses (including the PEC layer thickness) of multilayer composite membranes [5,7].

Based on the information available in the literature on the structural features of CS [8], we attempted to determine the structure of PECs formed at the interlayer boundary in CS-based multilayer composites $[4,5,7,9]$. Presumably, the process of CS structure formation in the PEC region affects the microstructure of both adjacent layers. The structure of the formed PEC is related to the strength and rate of the polyelectrolyte interaction. Since the formation of the PEC occurs when the polycationic CS gel film contacts the polyanion solution, a mutual diffusion of polymers occurs at the interlayer boundary. Thus, two processes-the mutual diffusion and the formation of polyelectrolyte contacts-occur simultaneously. In the case of a strong polyelectrolyte interaction (e.g., CS-SEC), mutual diffusion slows down as a result of poly-ion fixing interactions and a well-defined layer interface forms. In the case of weak polyelectrolyte interaction, the mutually diffusing polymers have time to undergo deeper penetration into the layers. As a result, a blurred interface is formed, as described in detail in [7]. Neither just how completely the polyelectrolyte contacts at the interface are realized in each case nor whether we know the strength of the contacts that are formed or how this correlates with the microstructure of the sample are clear. For this reason, in this work, we attempted to involve thermophysical methods in solving these questions.

A number of studies [10-13] have applied thermogravimetric analysis (TGA) and differential scanning calorimetry (DSC) to confirm the formation of PEC between CS and different polysaccharides (e.g., pectin, carboxymethyl cellulose, ALG, and HA). The most informative method for determination of the water state in polysaccharides and PECs is DSC. As shown previously [14,15], the degree of hydration of polysaccharides depends on the molecular and supramolecular structures of the polymers. The plasticizing action of water and the high hygroscopicity of CS hinder the determination of the glass transition temperature, thereby causing a considerable scatter of the experimental data $[16,17]$.

One common method for determining the temperature of relaxation transitions in polymers is dynamic mechanical analysis (DMA), which has a greater sensitivity for molecular motion compared with other methods of thermal analysis [18]. The DMA method has been used for the analysis of relaxation transitions in branched copolymers based on CS and dextran, as reported in [19]. In particular, that paper contains a detailed discussion of the contradictions in the literature related to the determination of the CS glass transition temperature. The thermophysical properties of CS in the basic and salt forms were also studied by DMA in [20]. The high glass transition temperatures obtained for CS confirm the conclusions made in [19].

An ALG-CS complex with various degrees of poly-ion interactions was studied by both TGA and DMA in [21]. The thermal properties and thermal stability of HA, CS, and PEC films were investigated using TGA in [11]. The thermal decomposition of the PEC 
film occurred at $\approx 280{ }^{\circ} \mathrm{C}$, and the TGA results showed a rapid increase in the thermal decomposition temperature of PEC films as the CS content increased. The PEC films in that paper were prepared by dissolving the two components at various ratios in an aqueous $50 \mathrm{wt} . \%$ formic acid solution.

The thermal properties of the CS/HA complex were studied in [22]. The PECs of chitosan and HA were prepared by mixing various weight ratios of two oppositely charged polymers at various $\mathrm{pH}$ values. DSC was used for quantitative determination of the amounts of freezing and non-freezing water. DSC, TGA, and XRD have been used to characterize CS/ALG polyelectrolyte complexes [23] prepared by freeze-drying a precipitate from sufficient mixtures of the two polymers. After the complex formation, the crystalline structure of CS disappeared, and the PECs showed an amorphous morphology. In [24], PEC membranes made by blending $84 \%$ deacetylated CS and ALG were investigated for use in a direct methanol fuel cell. XRD was used to observe the effects of blending on the crystallinity of the membranes. The thermal stability of the membranes was determined by thermal analysis.

Our examination of a series of multilayer CS-based composites revealed an effect of the structure and properties of the PEC layer on the properties of membranes $[4,9,25,26]$. A two-layer $\mathrm{CS}_{\mathrm{b}}-\mathrm{PEC}_{\mathrm{HA}}$ film was obtained after the conversion of CS from its salt form $\left(\mathrm{CS}_{\mathrm{s}}\right)$ to the basic form $\left(\mathrm{CS}_{\mathrm{b}}\right)$ and after removal of the HA layer. The thermal decomposition of the film was characterized by three peaks and a maximum weight loss rate at 220, 293, and $360^{\circ} \mathrm{C}$ [9]. The high-temperature peak at $360^{\circ} \mathrm{C}$ was considered to reflect the degradation of the $\mathrm{PEC}_{\mathrm{HA}}$ layer containing anhydrous CS. Two low-temperature peaks were attributed to the thermal decomposition of two CS polymorphs, as confirmed by X-ray diffraction.

Thus, thermal analysis approaches are widely used to study the properties of PECs based on natural and synthetic polymers. However, thermal analysis has not been used to study the PEC layer in multilayer composite films and membranes. The aims of the present work were to study the thermophysical properties of multilayer composite films based on CS and anionic polysaccharides (specifically SEC, ALG, and HA) and to investigate the effects of structurally different polyanions on the relaxation and the structural characteristics of multilayer CS/polyanion composites. The fundamental difference and complexity of the present research is the determination of the thermal characteristics of the structural elements formed during the formation of a multilayer composite containing a PEC layer in its composition. From this point of view, all of the studied objects are investigated for the first time and the information obtained is of great importance for understanding the process of multilayer PEC composite formation and its properties, including functional properties.

\section{Materials and Methods}

\subsection{Materials}

This study was performed using crab shell chitosan (Bioprogress, Shchelkovo, Russia) with a viscosity average molecular weight $\left(\mathrm{M}_{\eta}\right)$ of $1.6 \times 10^{5}$ and a degree of deacetylation of 0.80 [9], sodium hyaluronate (Shandong Focuchem Biotech Co., Qufu, Shandong, China) with $\mathrm{M}_{\eta}$ of $5.4 \times 10^{4}$ [27], sodium alginate (Qingdao Bright Moon Seaweed Group Co. Ltd., Qingdao, Shandong, China) with $\mathrm{M}_{\eta}$ of $1.3 \times 10^{5}$ [28], and sodium sulfoethyl cellulose with $\mathrm{M}_{\eta}$ of $1.4 \times 10^{4}$ and a degree of substitution of 0.80 (the sample was prepared and characterized according to [4]).

\subsection{Preparation of Composite Films}

Composite films were obtained using the layer-by-layer deposition of polymer solutions. A $2 \%$ CS solution in $2 \%$ acetic acid was deposited from a spinneret onto a balanced glass substrate and dried to the gel-like state. A $2 \%$ aqueous solution of polyanion was then deposited onto the surface of the layer, and the films were dried at room temperature. The resulting complex film (25-30 $\mu \mathrm{m}$ thick) can be considered a three-layer system containing chitosan acetate (salt form, $\mathrm{CS}_{\mathrm{s}}$ ), the polyanion, and the PEC layer formed between the two polyelectrolyte layers. Treatment of this film with $2 \%$ ammonia in ethanol transformed 
the $\mathrm{CS}_{\mathrm{s}}$ into the water-insoluble basic form $\left(\mathrm{CS}_{\mathrm{b}}\right)$, thereby allowing the removal of the water-soluble polyanion layer by extraction with water for analysis of the structure of the PEC layer. Various polyanions were used to prepare three-layer films $\left(\mathrm{CS}_{\mathrm{S}}-\mathrm{PEC} \mathrm{SEC}_{\mathrm{SEC}}-\mathrm{SEC}\right.$ $\mathrm{CS}_{\mathrm{S}}-\mathrm{PEC}_{\mathrm{HA}}-\mathrm{HA}$, and $\left.\mathrm{CS}_{\mathrm{s}}-\mathrm{PEC}_{\mathrm{ALG}}-\mathrm{ALG}\right)$ and two-layer films $\left(\mathrm{CS}_{\mathrm{b}}-\mathrm{PEC}_{\mathrm{SEC}}, \mathrm{CS}_{\mathrm{b}}-\mathrm{PEC}_{\mathrm{HA}}\right.$, and $\left.\mathrm{CS}_{\mathrm{b}}-\mathrm{PEC}_{\mathrm{ALG}}\right)$.

The structure of the composite films was compared by preparing a film containing an anhydrous polymorph of CS. For this, the $\mathrm{CS}_{\mathrm{s}}$ film was processed by hydrothermal treatment. In this case, the $\mathrm{CS}_{\mathrm{S}}$ film, weighing $0.23 \mathrm{~g}$, was placed into a $15 \mathrm{~mL}$ Teflon cell, which was $2 / 3$ filled with distilled water. After that, the hermetically sealed steel autoclave was heated in an oven to $200{ }^{\circ} \mathrm{C}$. The sample was held under isothermal conditions for $20 \mathrm{~min}$ at $100 \mathrm{~atm}$. The pressure inside the autoclave for the selected temperature was set in accordance with the cell filling factor based on the Kennedy table [29]. At the end of the temperature treatment, the autoclave was cooled down, together with the oven, to room temperature. The film was removed from the cell and dried in air at $60{ }^{\circ} \mathrm{C}$ to constant weight.

\subsection{Methods}

TGA was performed using a TG 209 F1 (Erich NETZSCH GmbH \& Co, Selb, Germany) setup in a temperature range from 30 to $600{ }^{\circ} \mathrm{C}$, again at a $10^{\circ} \mathrm{C} \cdot \mathrm{min}^{-1}$ heating rate, in argon medium. The sample mass was $2-3 \mathrm{mg}$.

DSC analysis of the samples was carried out using a DSC 204 F1 (Erich NETZSCH $\mathrm{GmbH} \& \mathrm{Co}$, Selb, Germany) heat flow differential scanning calorimeter in a temperature range from 30 to $250{ }^{\circ} \mathrm{C}$ in an argon atmosphere; the heating rate was $10{ }^{\circ} \mathrm{C} \cdot \mathrm{min}^{-1}$.

A DMA 242 C setup (Erich NETZSCH GmbH \& Co, Selb, Germany) was used to measure the temperature dependence of the dynamic mechanical characteristics of the films during stretching (Young's modulus $E^{\prime}$, loss modulus $E^{\prime \prime}$, and mechanical loss tangent $\operatorname{tg} \delta$ ). The measurements were carried out at a frequency of $1 \mathrm{~Hz}$ and a heating rate of $5{ }^{\circ} \mathrm{C} \cdot \mathrm{min}^{-1}$. The temperatures of the relaxation transitions were determined from the positions of the maxima or from inflexions of the curves for dynamic parameters.

The X-ray diffraction analysis was performed using a Miniflex 600 (Rigaku Technologies, Inc., Tokyo, Japan) diffractometer $(\mathrm{U}=40 \mathrm{kV}, \mathrm{J}=15 \mathrm{~mA}$, and a range of angles $2 \theta$ from 5 to 50$)$.

Cross-sectional images of the films were taken on a Scios scanning electron microscope (Field Electron and Ion Company, Hillsboro, OR, USA) with a FEG electron source.

\section{Results and Discussion}

\subsection{Thermal Analysis of the CS Polyanion Films}

Multilayer films were studied by thermal analysis (TGA and DSC), with the assumption that each layer has its own individual thermal stability parameters.

Figure 1 presents the TGA data (TG, solid line) and differential thermogravimetric analyses (DTG, dotted line) of CS in the salt form $\left(\mathrm{CS}_{\mathrm{S}}\right), \mathrm{SEC}$, and a three-layer film $\left(\mathrm{CS}_{\mathrm{S}}-\right.$ PEC $_{\text {SEC }}-S E C$ ). Each thermal decomposition process for $\mathrm{CS}_{\mathrm{S}}$ (Figure 1a, DTG curve) and SEC (Figure 1b, DTG curve) consists of one stage, with the maximum mass loss rates observed at 293 and $309{ }^{\circ} \mathrm{C}$, respectively. Thermal degradation of the $\mathrm{CS}_{\mathrm{S}}-\mathrm{PEC}_{\mathrm{SEC}}-\mathrm{SEC}$ composite (Figure 1c) is a more complex process; the differential curve of the mass loss is bimodal and contains two maxima (at 281 and at $308^{\circ} \mathrm{C}$ ), where the last maximum coincides with the temperature of the maximum decomposition rate of SEC (Figure 1b). The temperature maximum at $281{ }^{\circ} \mathrm{C}$ differs from the temperature of the maximum decomposition rate of $\mathrm{CS}_{\mathrm{s}}$ (Figure 1a), thereby allowing its attribution to the total decomposition of the PEC layer and $\mathrm{CS}_{\mathrm{s}}$. This is confirmed by a noticeable broadening of the DTG curve of the $\mathrm{CS}_{\mathrm{S}}-\mathrm{PEC}_{\mathrm{SEC}}-\mathrm{SEC}$ composite when compared to the curves of the original polymers. 


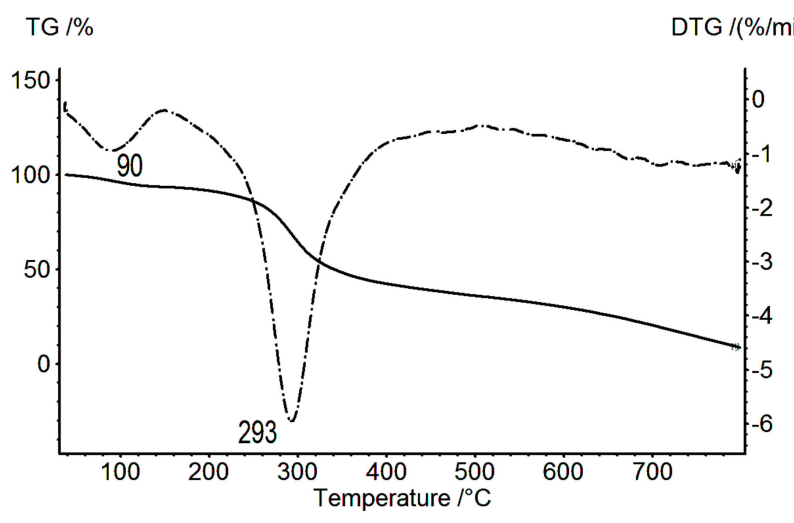

(a)

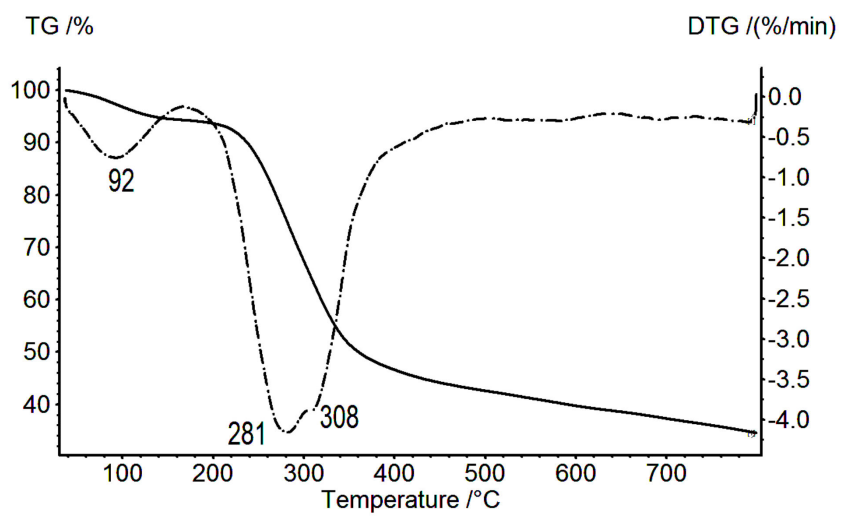

(c)

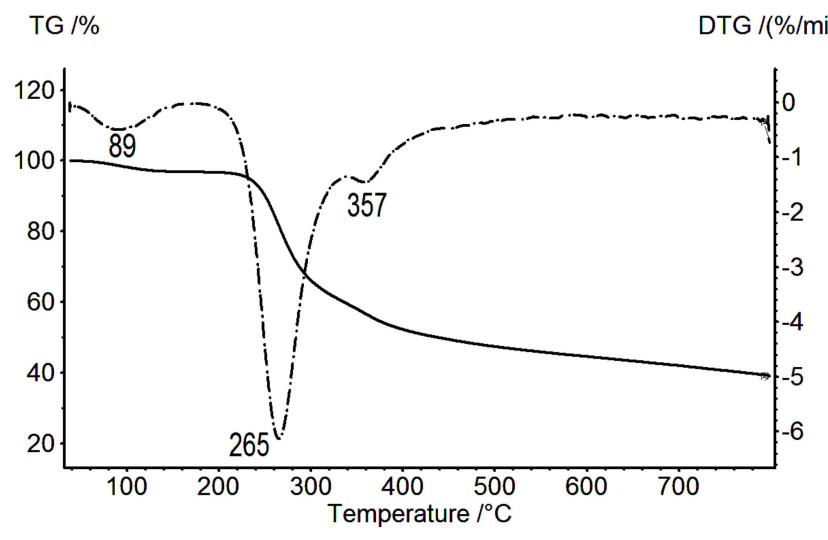

(e)

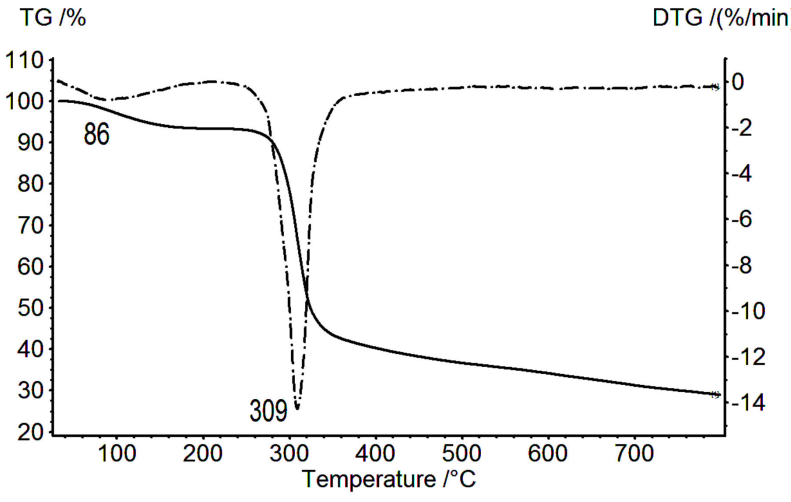

(b)
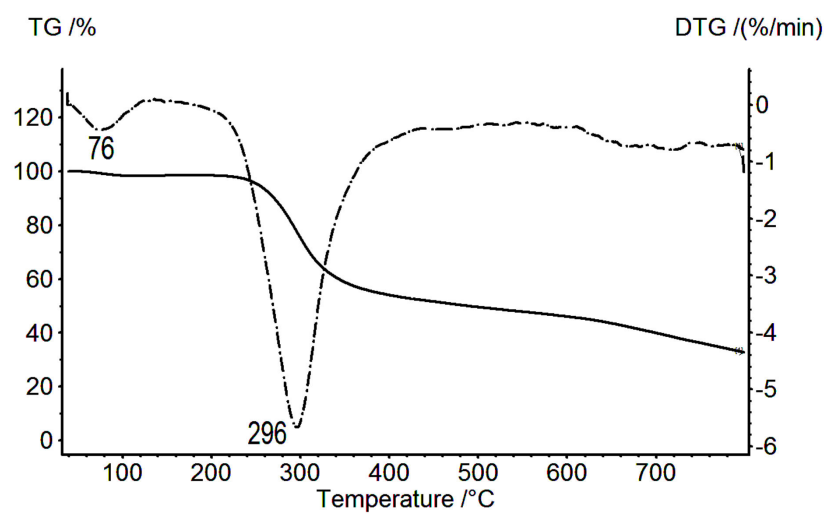

(d)

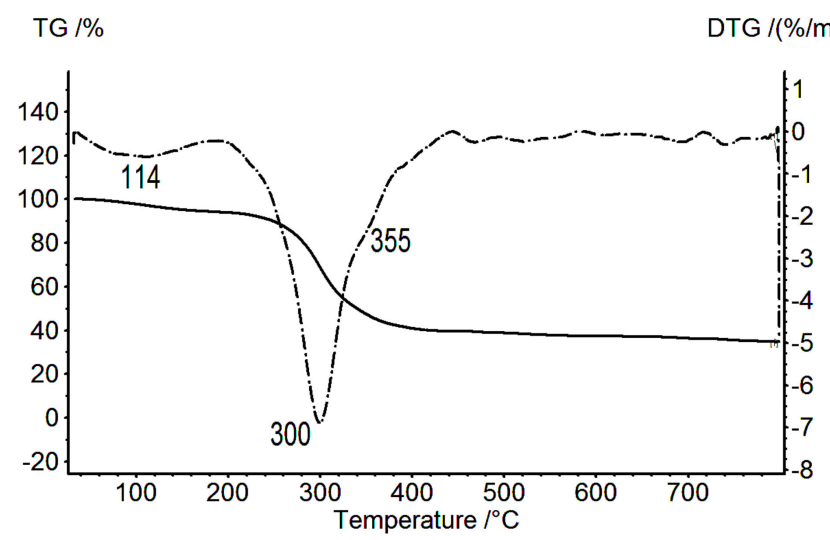

$(\mathbf{f})$

Figure 1. Thermogravimetric (TG; solid lines) and differential thermogravimetric (DTG; dotted lines) curves: (a) $\mathrm{CS}_{\mathrm{S}}$, (b) SEC, (c) $\mathrm{CS}_{\mathrm{s}}-\mathrm{PEC}_{\mathrm{SEC}}-\mathrm{SEC}$, (d) $\mathrm{CS}_{\mathrm{b}},(\mathbf{e}) \mathrm{CS}_{\mathrm{b}}-\mathrm{PEC} \mathrm{SEC}$, and (f) $\mathrm{CS}_{\mathrm{b}}$ after hydrothermal treatment.

The thermal analysis of two-layer films containing $\mathrm{CS}_{\mathrm{b}}$ and PEC layers was particularly informative. The two-layer $\mathrm{CS}_{\mathrm{b}}-\mathrm{PEC}_{\mathrm{SEC}}$ film demonstrates two decomposition peaks located at 265 and $357^{\circ} \mathrm{C}$ (Figure 1e); the first peak does not coincide with the decomposition maxima of $\mathrm{CS}_{\mathrm{b}}$ (Figure 1d), whereas the second peak (at $357^{\circ} \mathrm{C}$ ) was not observed on the TG and DTG curves presented in Figure 1a-c.

Figure $1 \mathrm{f}$ shows the TGA curve for a $\mathrm{CS}_{\mathrm{s}}$ film that had been subjected to hydrothermal treatment at $200{ }^{\circ} \mathrm{C}$ for $20 \mathrm{~min}$. Hydrothermal treatment is known to transform a hydrated $\mathrm{CS}_{\text {s }}$ polymorph into an anhydrous crystalline polymorph [6]. This transformation is ac- 
companied by the appearance of intense reflections in the X-ray diffractograms $(2 \theta=15$, 21 and $22.4^{\circ}$ ). We observed a similar pattern in our previous work [5] with a $\mathrm{CS}_{\mathrm{s}}$ sample subjected to hydrothermal treatment. At the same time, a weak reflection at $2 \theta=10^{\circ}$ was also registered, indicating the presence of hydrated CS in the sample [5]. According to [6], the presence of this reflection and its absence in the diffractogram obtained after hydrothermal treatment of the film can be explained by the presence of water molecules between the CS polymer chains; these molecules are arranged along the (010) crystallographic plane. Since the thermal decomposition curve of this sample (Figure 1f) is bimodal, we assumed, in our case, that two CS polymorphs (hydrated and anhydrous) are present in the sample. Indeed, the decomposition peak at $300{ }^{\circ} \mathrm{C}$ is very close to the decomposition peak of $\mathrm{CS}_{\mathrm{b}}$ (Figure 1d). Therefore, the high-temperature maximum at $355^{\circ} \mathrm{C}$ can be attributed to anhydrous CS. Completely anhydrous CS can be obtained after the sample was subjected to orientation tension in water at $95^{\circ} \mathrm{C}$ before hydrothermal treatment [30].

A bimodal decomposition curve was also observed for the $\mathrm{CS}_{\mathrm{b}}-\mathrm{PEC}_{\mathrm{SEC}}$ sample (Figure 1e). The weakly pronounced high-temperature peak at $357^{\circ} \mathrm{C}$ can be attributed to the anhydrous CS polymorph. The presence of this modification is confirmed by the appearance of the signal at $2 \theta=15^{\circ}$ in the diffractograms [6]. The first peak at $265^{\circ} \mathrm{C}$ may be connected with the decomposition of the hydrated CS polymorph. Conformational variants for CS are not resolved for most polymorphs. For one of the hydrated forms of CS, the crystal structure was determined based on X-ray diffraction data [31].

Figure 2 presents the TG and DTG data obtained for the ALG film and the composite $\mathrm{CS}_{\mathrm{s}}-\mathrm{PEC}_{\mathrm{ALG}}-\mathrm{ALG}$ and $\mathrm{CS}_{\mathrm{b}}-\mathrm{PEC}_{\mathrm{ALG}}$ films. The thermo-destruction of the $\mathrm{CS}_{\mathrm{s}}-\mathrm{PEC}_{\mathrm{ALG}}-$ ALG composites occurs in two stages, with the maximum mass loss rates observed at 235.0 and $292{ }^{\circ} \mathrm{C}$ (Figure 2b). The first temperature essentially coincides with the temperature of the destruction of the ALG polyanion (Figure 2a), while the second maximum is close to the degradation temperature of CS. The second observation is explained by the presence of a loose network of polyelectrolyte contacts (ionic crosslinks), and it may indicate a low stability of the obtained $\mathrm{PEC}_{\mathrm{ALG}}$. A significant difference is also noted in the thermal behavior of the multilayer composites in the case of formation of a weak PEC.

In the case of the $\mathrm{CS}_{\mathrm{b}}-\mathrm{PEC}_{\mathrm{ALG}}$ composite layer (Figure 2c), only one destruction temperature was registered in the DTG experiments $\left(287^{\circ} \mathrm{C}\right)$, and this temperature differed from the degradation temperatures of the individual components of this complex. Presumably, this corresponds to the degradation of one of the CS polymorphs. No degradation is registered for the PEC incorporated into the $\mathrm{CS}_{\mathrm{b}}-\mathrm{PEC} \mathrm{ALG}$ two-layer film, indicating an apparent overlap of the CS and PEC thermo-destruction processes in the $\mathrm{CS}_{\mathrm{b}}-\mathrm{PEC}_{\mathrm{ALG}}$ two-layer film (as indicated by the large half-width of its DTG peak, Figure 2c). The weak CS structurization in the $\mathrm{CS}_{\mathrm{b}}-\mathrm{PEC}$ ALG composite is related to the ALG structure, which leads to the formation of a diffuse PEC layer [7].

The CS/HA composite occupies an intermediate position relative to the other two composites [9]. Figure 3 a shows the TGA data for two-layer samples $\mathrm{CS}_{\mathrm{b}}-\mathrm{PEC}_{\mathrm{SEC}}$ (solid line), $\mathrm{CS}_{\mathrm{b}}-\mathrm{PEC}_{\mathrm{ALG}}$ (dash-dotted line), and $\mathrm{CS}_{\mathrm{b}}-\mathrm{PEC}_{\mathrm{HA}}$ (dotted line). The weight loss is significantly higher for the $\mathrm{CS}_{\mathrm{b}}-\mathrm{PEC}_{\mathrm{HA}}$ two-layer film than for the other composites. A comparison of the effect of the type of polyanion on the structure of the PEC layer is depicted in Figure 3b, which shows the results for the thermal decomposition of two-layer films obtained using polyanions of different functionality and structure.

The thermal degradation of the $\mathrm{CS}_{\mathrm{b}}-\mathrm{PEC}_{\mathrm{HA}}$ composite film proceeds in three stages (Figure $3 b$ ), with a maximum weight loss rate at 220,293 , and $360^{\circ} \mathrm{C}$. The presence of at least two polymorphic modifications of CS (hydrated and anhydrous) in the $\mathrm{CS}_{\mathrm{b}}-\mathrm{PEC}_{\mathrm{HA}}$ film is confirmed by the X-ray diffraction as evidenced by the signal at $2 \theta=10^{\circ}$, typical for the hydrated CS, and at $2 \theta=15^{\circ}$, typical for the anhydrous CS polymorph [9]. The peaks at 220 and $293{ }^{\circ} \mathrm{C}$ can be attributed to the degradation of the hydrated CS polymorph, while the peak at $360{ }^{\circ} \mathrm{C}$ is associated with the degradation of the $\mathrm{PEC}_{\mathrm{HA}}$ containing the anhydrous polymorph of CS in its structure. Unlike the CS/SEC polymer pair, the CS/HA pair shows a more intense signal for the hydrated CS than for the anhydrous CS. 
Therefore, the ability of HA to retain water influences the chemical composition of the film in the region of the PEC. Consequently, the PEC layer for this pair is more hydrophilic, as indicated by the higher swelling degree of the $\mathrm{PEC}_{\mathrm{HA}}$ isolated from the three-layer

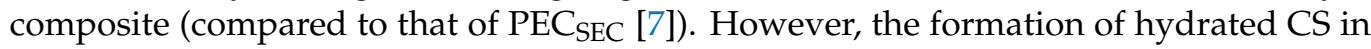
this region is only indirectly related to this property of HA, which, in a way, is a supplier of construction materials (water molecules) for the CS-HA interphase boundary. At the same time, as demonstrated experimentally, the formation of the CS structure in a near-boundary area proceeds during contact between CS film (in the salt form $\mathrm{CS}_{\mathrm{s}}$ ) and the aqueous solution of HA, and this formation is followed by the removal of water (drying in air).

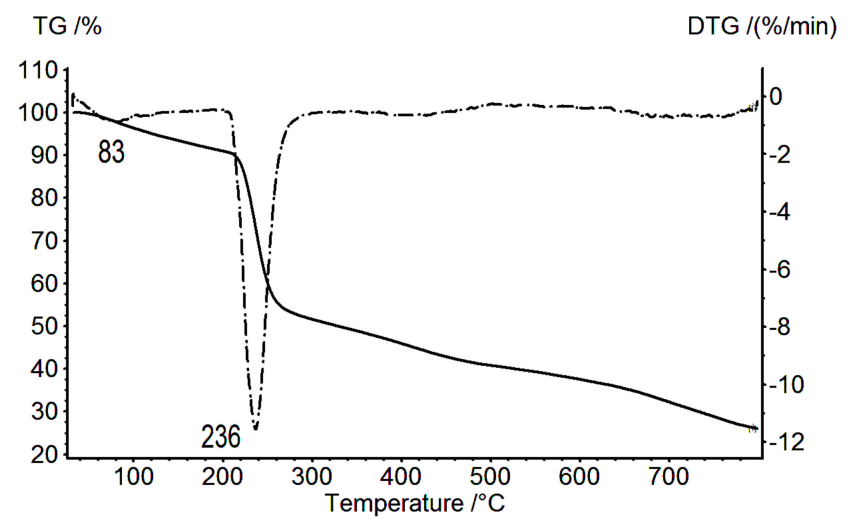

(a)

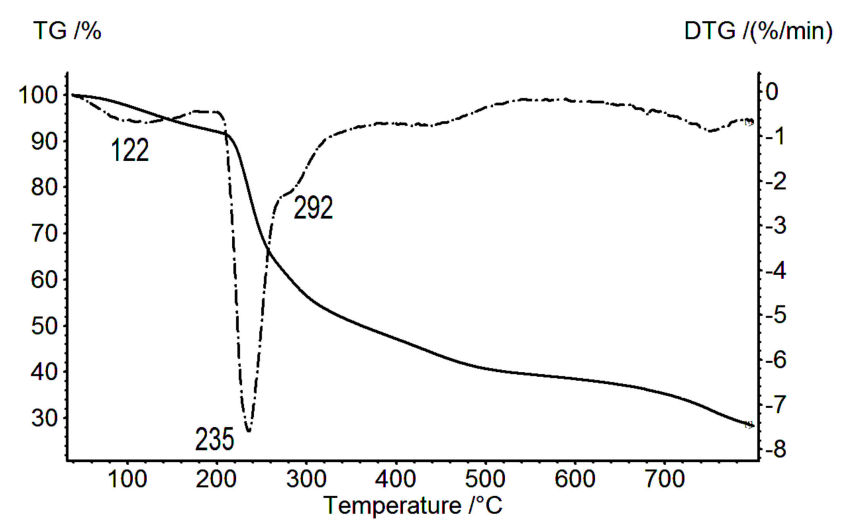

(b)

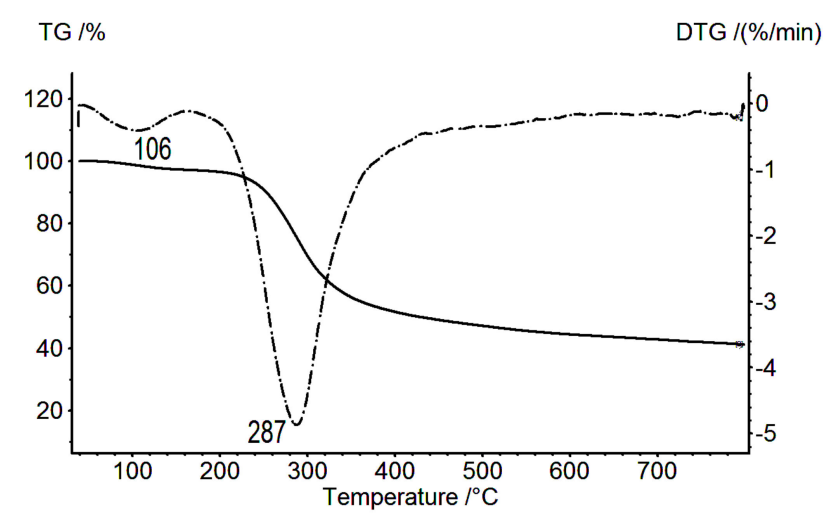

(c)

Figure 2. Thermogravimetric (TG; solid lines) and differential thermogravimetric (DTG; dotted lines) curves: (a) $\mathrm{ALG}$, (b) $\mathrm{CS}_{\mathrm{s}}-\mathrm{PEC}_{\mathrm{ALG}}-\mathrm{ALG}$, and (c) $\mathrm{CS}_{\mathrm{b}}-\mathrm{PEC}_{\mathrm{ALG}}$. 


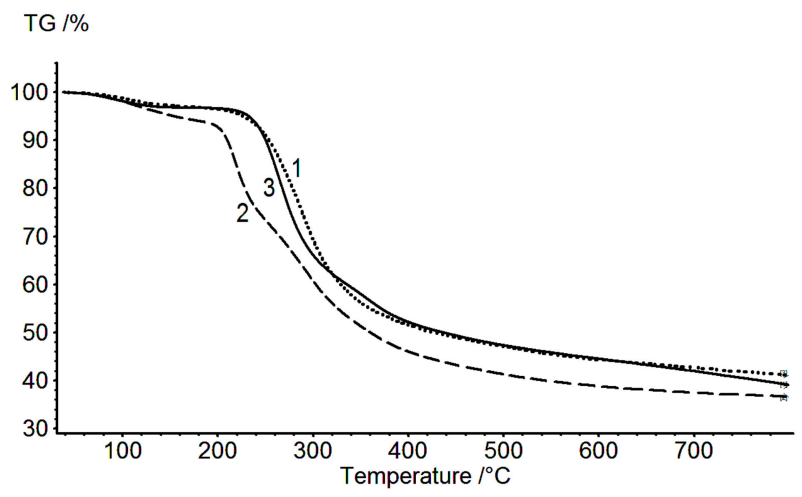

(a)

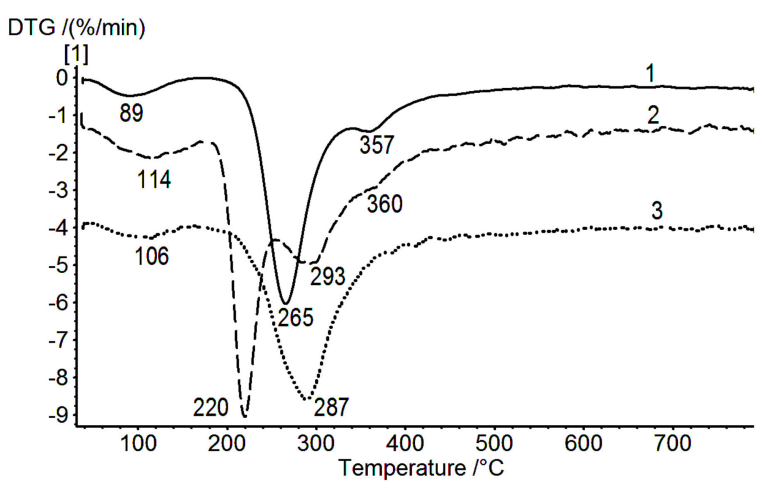

(b)

Figure 3. TG (a) and DTG (b) curves: $\mathrm{CS}_{\mathrm{b}}-\mathrm{PEC}_{\mathrm{SEC}}(1), \mathrm{CS}_{\mathrm{b}}-\mathrm{PEC}_{\mathrm{HA}}(2)[9]$, and $\mathrm{CS}_{\mathrm{b}}-\mathrm{PEC}_{\mathrm{ALG}}$ (3).

In this case, at least two processes occur: one is an interaction between the oppositely charged groups (ionic crosslinking), and the other is diffusion of the polyanion (HA) into the region of the $\mathrm{CS}_{\mathrm{s}}$ gel film. Each of these processes is accompanied by changes in the "instantaneous" polysaccharide conformation, and each influences the polymer conformational features in the resulting composite. Since HA is a weak acid (i.e., it contains carboxyl groups), the rate of the exchange reaction involved in the formation of PEC is comparable to the rate of polysaccharide diffusion into the interphase region (as observed during the formation of certain simplex membranes [9]). These processes then lead to the formation of a multilayer film containing polymer layers of various microstructures with a more diffuse interphase boundary than is found in the CS-SEC film [4,7].

The results discussed in the present work demonstrate that a conformational rearrangement in the PEC area of the CS/HA composite leads to the formation of two polymorphs, with the hydrated form predominating. The high-temperature peak observed during thermal degradation of CS/HA, which corresponds to the anhydrous form, is less pronounced than in the case of CS/SEC (Figure 3b, curves 1 and 2). When CS interacts with a strong

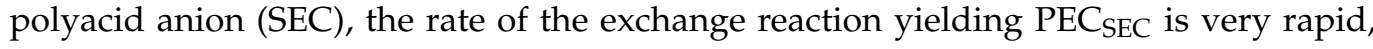
whereas the diffusion of polysaccharides at the interphase boundary is insignificant [4]. In this case, only the anhydrous CS polymorph is formed in the $\mathrm{PEC}_{\mathrm{SEC}}$ region, as demonstrated above. The most interesting fact is that conformations of the polymorphs formed in $\mathrm{PEC}_{\mathrm{HA}}$ and $\mathrm{PEC}_{\mathrm{SEC}}$ differ from the conformations of $\mathrm{CS}_{\mathrm{b}}$ and the initial $\mathrm{CS}_{\mathrm{s}}$, as seen from the above data (Figures 1 and 3). These conclusions agree well with recent reports on two-layer film structures $[4,7,9]$.

The polyanions that lead to the formation of these two groups of PECs differ in the nature of the ionic groups in their structure. In the first case, the ionic groups are strong acid salts ( $\mathrm{R}-\mathrm{SO}_{3}-$ for SEC), whereas, in the second case, they are weak acid salts (carboxylate groups for HA and ALG). The formation of a PEC between CS and a strong acid salt proceeds rapidly, whereas in the second case, the process is relatively slow. This slow complex formation is accompanied by interpenetration of the polymers, so that the interface between the formed layers becomes diffuse. Presumably, the weak dissociation of a polyacid leads to the coexistence of two forms (acidic and ionic/salt forms) in the resulting film.

No PEC degradation is registered for the $\mathrm{CS}_{\mathrm{b}}-\mathrm{PEC}$ ALG two-layer film (Figure 3b, curve 3). The low degree of CS structuring in the $\mathrm{CS}_{\mathrm{b}}-\mathrm{PEC}_{\mathrm{ALG}}$ composite is associated with the irregular ALG structure (block copolymer of $(1 \rightarrow 4)$ linked $\beta$-D-mannuronate and $\alpha$-L-guluronate), which leads to a lesser degree of ionic cross-linking.

All of the TGA and DTG curves depicted in Figure 3 indicate a weight loss before the onset of thermal destruction; this loss is associated with the release of water from the twolayer CS-based composites examined here. The smallest maximum in the rate of weight loss in this region $\left(89^{\circ} \mathrm{C}\right)$ is observed for the $\mathrm{CS}_{\mathrm{b}}-\mathrm{PEC}_{\mathrm{SEC}}$ two-layer film. The completion 
of the water release for this sample is recorded at $120^{\circ} \mathrm{C}$. As shown previously $[10,14]$, water bound by hydrogen bonds with polysaccharides is released in this region. The release of water associated with carboxyl groups is shifted toward higher temperatures (above $160^{\circ} \mathrm{C}$ ). In our case, the carboxyl groups contain two poly-ions: HA and ALG. Consequently, the shift in the maxima of the rates of release of bound water observed on the DTG curves (Figure 3b, curves 2 and 3 ) is quite expected. In this case, the release of bound water is recorded until the beginning of thermal decomposition. The amount of released bound water was estimated by the DSC method and amounted to 211.5, 457.5, and $320.5 \mathrm{~J} / \mathrm{g}$ for $\mathrm{CS}_{\mathrm{b}}-\mathrm{PEC}_{\mathrm{SEC}}, \mathrm{CS}_{\mathrm{b}}-\mathrm{PEC}_{\mathrm{HA}}$, and $\mathrm{CS}_{\mathrm{b}}-\mathrm{PEC}_{\mathrm{ALG}}$, respectively.

\subsection{Scanning Electron Microscopy}

Comparative analysis of SEM images of cross sections of multilayer composites revealed clear contouring of the PEC layers in CS/SEC composites (Figure 4a). In other cases (e.g., CS/HA sample), a boundary emerged between the CS and the polyanion, but the PEC layer was poorly visualized (Figure $4 b$ ). The PEC layer in the $\mathrm{CS}_{\mathrm{s}}-\mathrm{PEC}_{\mathrm{SEC}}-\mathrm{SEC}$ film is dense, while that in the $\mathrm{CS}_{\mathrm{s}}-\mathrm{PEC}_{\mathrm{HA}}-\mathrm{HA}$ film is more loose, fuzzy, and contains defects. These data are in a good agreement with TGA data discussed above.

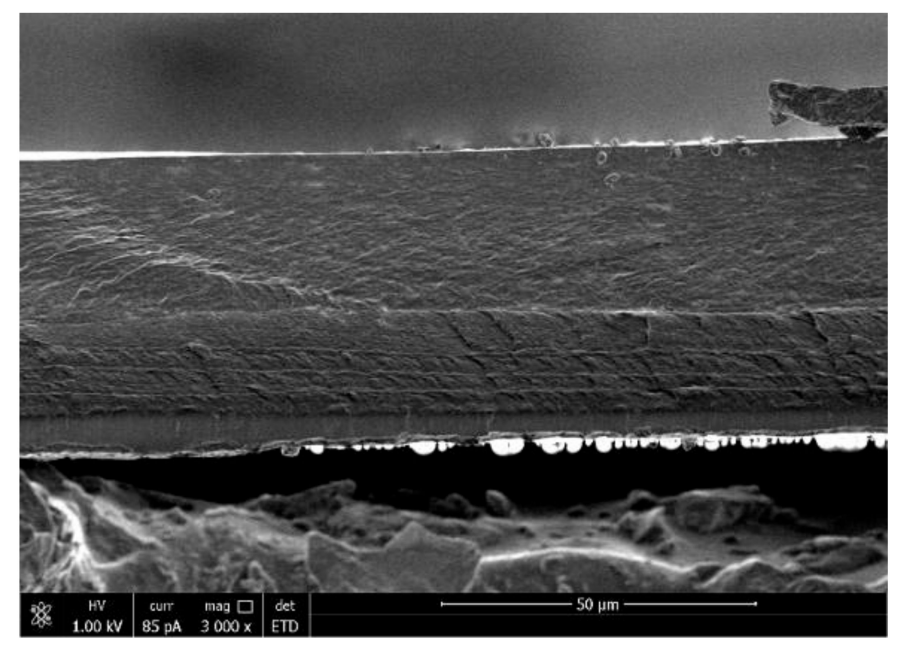

(a)

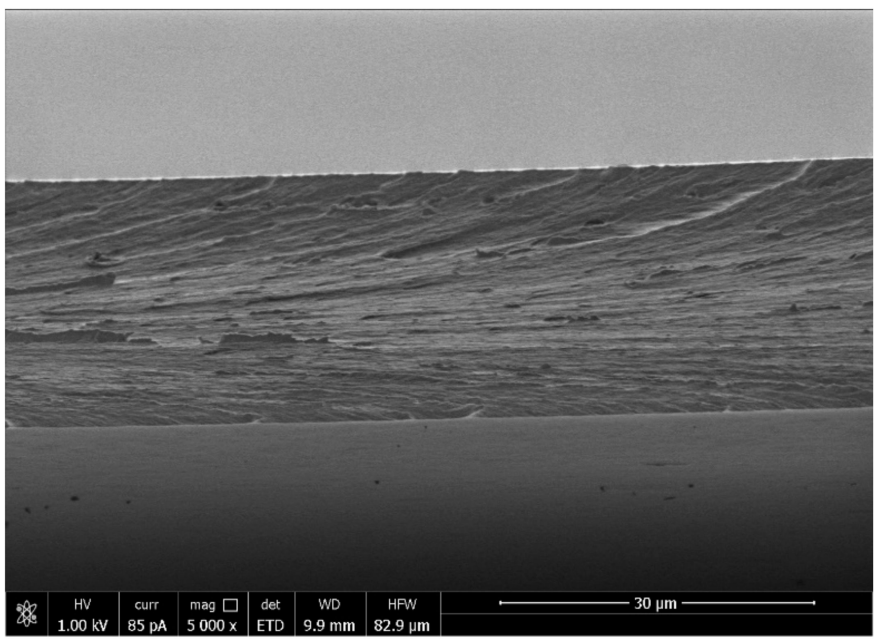

(b)

Figure 4. SEM images of cross sections of $\mathrm{CS}_{\mathrm{S}}-\mathrm{PEC}_{\mathrm{SEC}}-\mathrm{SEC}(\mathbf{a})$ and $\mathrm{CS}_{\mathrm{S}}-\mathrm{PEC}_{\mathrm{HA}}-\mathrm{HA}(\mathbf{b})$.

\subsection{X-ray Diffraction Analysis of the CS Polyanion Films}

Unlike the X-ray diffraction patterns presented in $[7,9]$, a more detailed X-ray diffraction analysis was performed for the two-layer $\mathrm{CS}_{\mathrm{b}}-\mathrm{PEC}_{\mathrm{SEC}}$ and $\mathrm{CS}_{\mathrm{b}}-\mathrm{PEC}_{\mathrm{HA}}$ samples (Figure 5). This analysis was not carried out for the $\mathrm{CS}_{\mathrm{b}}-\mathrm{PEC}_{\mathrm{ALG}}$ sample because of its diffuse PEC layer and the weak signal in the region $2 \theta: \approx 15^{\circ}$.

Under certain conditions, many polymers are known to crystallize and form crystal lattices throughout the whole volume of a sample (or in a portion of a sample). The diffraction maxima in X-ray patterns were defined by conducting a profile analysis (plotting Gaussian functions [32], which takes into account the various types of peak widening (including instrumental distortion, etc.), thereby allowing refinement of the peak positions. Analysis of the X-ray diffractograms demonstrated that the formation of the $\mathrm{CS}_{\mathrm{b}}-\mathrm{PEC}_{\mathrm{SEC}}$ composite is accompanied by crystallization of the CS chains, with a prevailing appearance of the anhydrous CS polymorph. The X-ray patterns contain an intense reflection at $2 \theta \approx 15^{\circ}$ (the lattice spacing $d=5.85 \AA$ ); this reflection is typical of an anhydrous polymorph. In addition, a weak reflection at $2 \theta, \approx 10^{\circ}(d=7.62 \AA)$, occurs that is attributed to hydrated CS.

By contrast, the X-ray diffractograms of the $\mathrm{CS}_{\mathrm{b}}-\mathrm{PEC}_{\mathrm{HA}}$ are quite different. The reflections at $2 \theta \approx 15^{\circ}(d=5.96 \AA)$ and $\approx 10^{\circ}(d=8.87 \AA)$ have similar intensities, indicating the presence of equal proportions of hydrated and anhydrous CS modifications in the 
film. One explanation for the differences in the interplanar distances in the hydrated phase of these two samples may be that the polymer molecules in a film are not completely packed into a crystal lattice; rather, the crystalline areas are interspersed among amorphous regions, thereby creating various defects in the polymer packing. These differences are related to specific features of the interaction of SEC and HA chains with CS (molecular structure, degree of substitution by polar groups, etc.). The relative degrees of crystallinity for these samples were estimated according to the intensity conservation law, which holds that intensity is determined by the volume integral of the electron density squared of an object [32]. The following degrees of crystallinity were found: $35.3 \%$ for $\mathrm{CS}_{\mathrm{b}}-\mathrm{PEC}_{\mathrm{SEC}}$ and $27.0 \%$ for $\mathrm{CS}_{\mathrm{b}}-\mathrm{PEC}_{\mathrm{HA}}$. A noticeable difference was observed in the thermal behavior of the multilayer composites when a weak PEC was formed.

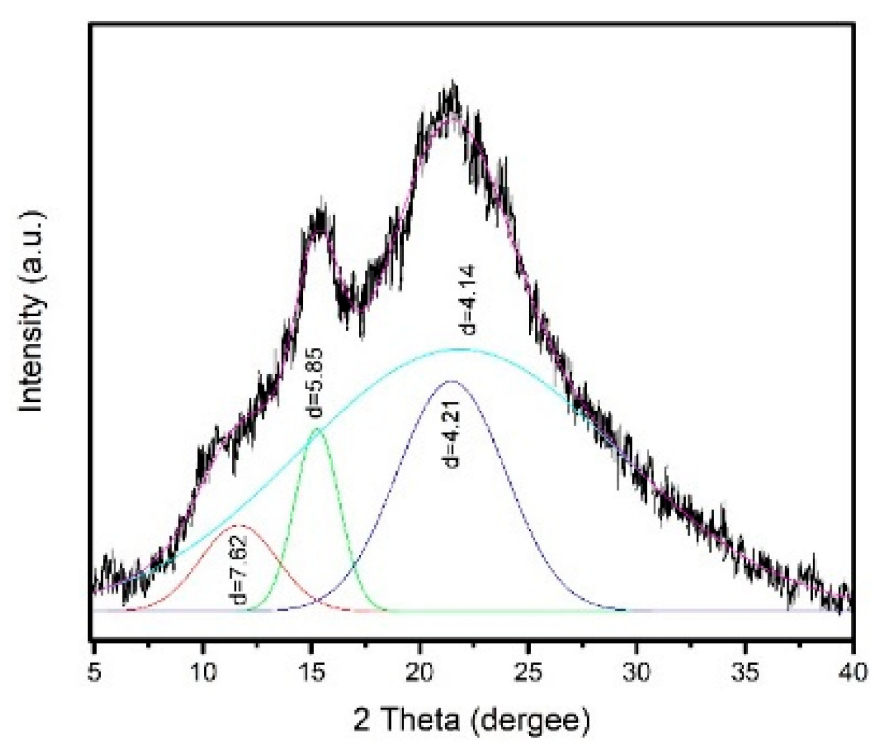

(a)

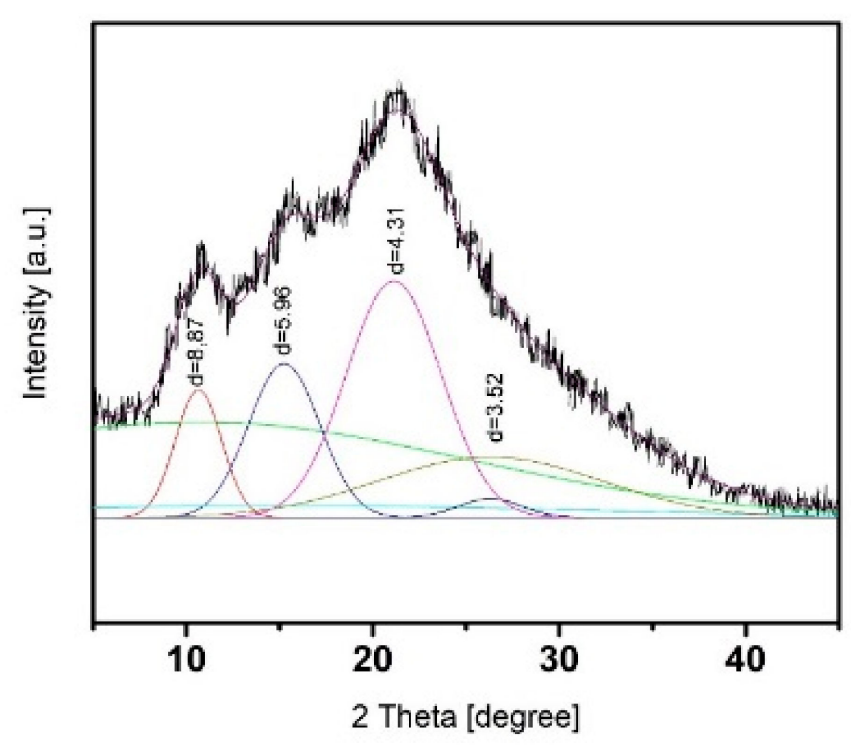

(b)

Figure 5. X-ray diffractograms of two-layer films (after removal of the water-soluble polyanion layer): (a) $\mathrm{CS}_{\mathrm{b}}-\mathrm{PEC}_{\mathrm{SEC}}$; (b) $\mathrm{CS}_{\mathrm{b}}-\mathrm{PEC}_{\mathrm{HA}}$, obtained from the PEC side.

\subsection{Dynamic Mechanical Analysis of the CS Polyanion Films}

The influence of the PEC layer (and, therefore, the factors determining its structural and morphological features) should manifest in the relaxation properties of the composites, particularly in the glass transition temperatures. The temperatures of the relaxation transitions were estimated from the temperatures of the maxima or inflexions on the curves $\operatorname{tg} \delta$, which describe the dynamic parameters of the samples.

During the formation of a strong PEC between CS and SEC, the two-layer and threelayer composites are characterized by only a single glass transition temperature (Figure 6, curves 3 and 2, respectively). As can be seen, no noticeable transitions were observed up to $200{ }^{\circ} \mathrm{C}$ for all samples. The week maxima of $\operatorname{tg} \delta$ in the $150-200^{\circ}$ region (Figure 6, curve 4 ) is related to molecular mobility of chitosan caused by the removal of absorbed and residues of acetic acid [20].

The maxima for the $\operatorname{tg} \delta \mathrm{vs}$. $T$ curves correspond to the glass transition temperatures

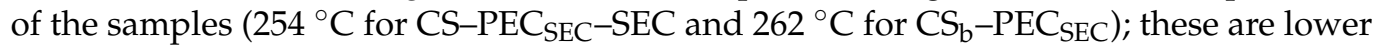
than the glass transition temperature for $\mathrm{CS}_{\mathrm{b}}\left(265^{\circ} \mathrm{C}\right)$ but higher than the glass transition temperature for SEC $\left(248{ }^{\circ} \mathrm{C}\right)$. Therefore, upon formation of a CS/SEC polyelectrolyte complex, each two-layer and three-layer composite demonstrates a single glass transition temperature (Figure 6, curves 3 and 2, respectively) and can be considered an integrated system that represents a combination of components at the molecular level. 


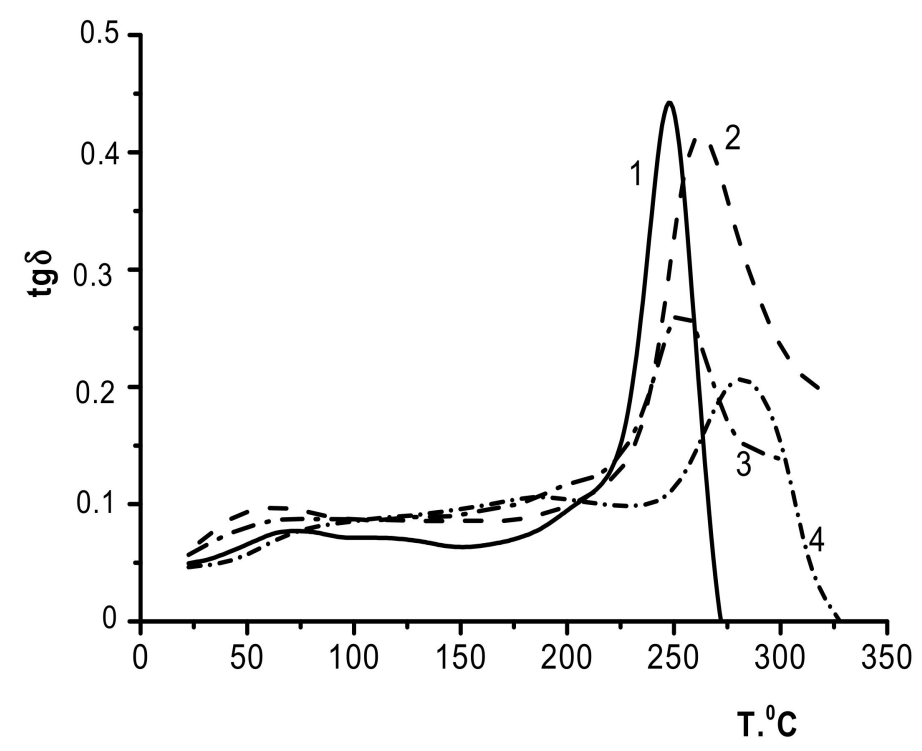

Figure 6. Temperature dependences of the mechanical loss tangent: $1, \mathrm{SEC} ; 2, \mathrm{CS}_{\mathrm{b}}-\mathrm{PEC}_{\mathrm{SEC}} ; 3, \mathrm{CS}_{\mathrm{s}}-$ PEC $_{\text {SEC }}-$ SEC; and $4, \mathrm{CS}_{\mathrm{b}}$.

We made several attempts to subject the three-layer $\mathrm{CS}_{\mathrm{S}}-\mathrm{PEC}_{\mathrm{HA}}-\mathrm{HA}$ films to DMA; however, these attempts were not successful. The samples broke at $210-215^{\circ} \mathrm{C}$ (which approximately corresponded to the HA glass transition temperature). Similarly, the twolayer $\mathrm{CS}_{\mathrm{b}}-\mathrm{PEC}_{\mathrm{HA}}$ samples were successfully tested only at temperatures not exceeding $350{ }^{\circ} \mathrm{C}$, indicating that the deformation abilities of the component layers are virtually the same.

Figure 7 presents the temperature dependence of $\operatorname{tg} \delta$ for the HA film (curve 1), the two-layer CS-PEC $\mathrm{HA}_{\mathrm{HA}}$ film (curve 2), and the $\mathrm{CS}_{\mathrm{b}}$ film (curve 3). The $\operatorname{tg} \delta$ curve for the two-layer film has a maximum at $255{ }^{\circ} \mathrm{C}$, which does not coincide with any of the glass transition temperatures of the individual components (i.e., $\mathrm{CS}_{\mathrm{b}}$ and HA, at 265 and $203{ }^{\circ} \mathrm{C}$, respectively). This curve also contains a shoulder in the low-temperature region that corresponds to the HA glass transition point. This transition can be explained by the presence of a HA phase that develops after the formation of PEC due to the mutual diffusion of the polymer counterions [9].

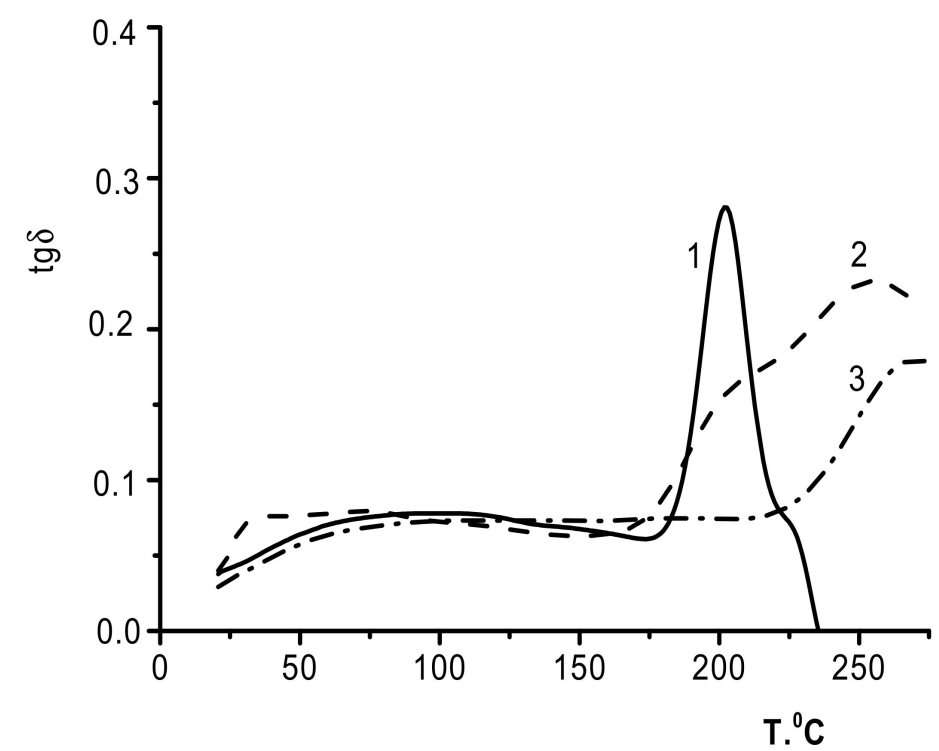

Figure 7. Temperature dependence of the mechanical loss tangent: $1, \mathrm{HA} ; 2, \mathrm{CS}_{\mathrm{b}}-\mathrm{PEC}_{\mathrm{HA}}$; and $3, \mathrm{CS}_{\mathrm{b}}$. 
The temperature dependence of $\operatorname{tg} \delta$ obtained for $\mathrm{CS}_{\mathrm{s}}-\mathrm{PEC} \mathrm{ALG}_{\mathrm{ALG}}-\mathrm{ALG}$ (Figure 8, curve 1) contains two maxima $\left(214^{\circ} \mathrm{C}\right.$ and $\left.260{ }^{\circ} \mathrm{C}\right)$; these two glass transition temperatures differ only slightly from those of the film components (ALG and CS, curves 4 and 3, respectively).

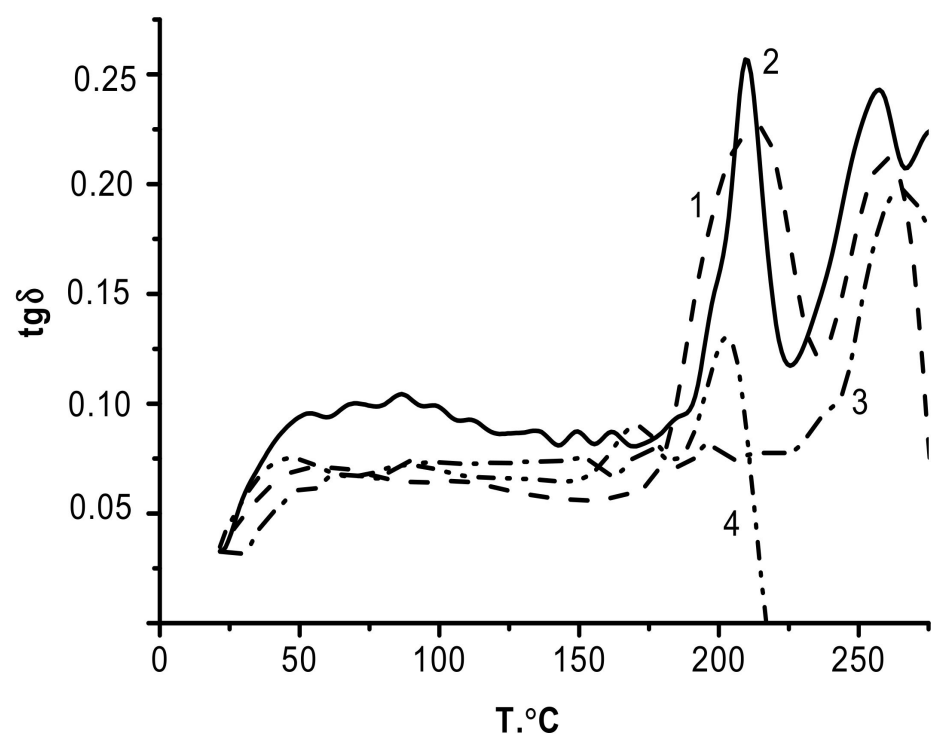

Figure 8. Temperature dependence of the mechanical loss tangent: $1, \mathrm{CS}_{\mathrm{s}}-\mathrm{PEC}_{\mathrm{ALG}}-\mathrm{ALG} ; 2, \mathrm{CS}_{\mathrm{b}}-$ $\mathrm{PEC}_{\mathrm{ALG}} ; 3, \mathrm{CS}_{\mathrm{b}}$; and 4, ALG.

Therefore, the ALG and CS layers in the $\mathrm{CS}_{\mathrm{S}}-\mathrm{PEC}_{\mathrm{ALG}}-\mathrm{ALG}$ composite retain their intrinsic glass transition temperatures, and the formation of the interlayer PEC $\mathrm{ALG}_{\text {complex }}$ does not influence the relaxation behavior of the neighboring layers. Note that the $\operatorname{tg} \delta$ dependence for $\mathrm{CS}_{\mathrm{b}}-\mathrm{PEC}_{\mathrm{ALG}}$ has a similar bimodal pattern. In this case, the peaks corresponding to the two glass transition temperatures have significantly lower half-widths and are shifted toward higher temperatures. One unexplained feature is why the DMA curves of the two-layer $\mathrm{CS}_{\mathrm{b}}-\mathrm{PEC}_{\mathrm{ALG}}$ sample contain a peak with a glass transition temperature close to that of the polyanion, even after the removal of the ALG layer. This is likely due to the slower PEC formation in the case of layer-by-layer deposition of ALG on the CS gel-film.

At the same time, an effect of mutual diffusion prevails in the ionic interactions, which then allows for recording the main $\alpha$-relaxation transition $\left(T_{g}\right)$ of ALG.

The polyacids described here can be conventionally divided into two groups according to their abilities to dissociate (i.e., weak and strong polyacids). The rate of formation of a PEC is slower between CS and a weak polyacid anion (HA or ALG) than it is between CS and a strong polyacid anion (SEC). The complex forms rather gradually, so the conformational rearrangements have sufficient time to occur in the swollen polymer. The differences in the trends of the temperature dependences of the mechanical loss tangents for HA and ALG can be assumed to arise due to the different conformational mobilities of HA and ALG. In this connection, our future work will involve in-depth computer modeling studies of the structure of the composites near the polyanion/CS interphase boundary.

\section{Conclusions}

The results obtained in this work suggest that the structure of the PEC layer in a multilayer polymer composite is the feature that controls the relaxation and thermal properties of that composite. The influence of a PEC on the properties of different CSbased composites decreases in the order CS/SEC > CS/HA > CS/ALG, and this effect is more pronounced in two-layer films. Our conclusions agree with the reported data on the influence of the PEC layer on the structural organization and morphology of various composites. 
The experimental curves for the thermal degradation of the CS/SEC composite were bimodal, indicating the presence of two CS polymorphs (i.e., hydrated and anhydrous). The two-layer and three-layer composites containing the same polyelectrolyte pair show single glass transition temperatures, indicating that they can be considered integrated systems. The properties of these composites arise due to the presence of strong acid anions $\left(-\mathrm{SO}_{3}{ }^{-}\right)$in the SEC and the complementarity of the SEC structure with that of CS.

Structural studies of two-layer CS/HA and CS/SEC films confirmed the difference in the structural organization of the PEC layers. The formation of the CS/SEC composite is accompanied by crystallization of the CS chains and the formation of a predominantly anhydrous CS polymorph. For the CS/HA composite, the hydrated and anhydrous CS polymorph are present in comparable proportions.

The thermal degradation behavior of the CS/HA sample shows that, in the PEC region, CS undergoes a conformational rearrangement to form two polymorphs with predominant hydrated modifications. The observed glass transition temperature of the two-layer film does not coincide with that of either the $\mathrm{CS}_{\mathrm{b}}$ or the HA glass transition values, although the curve contains a shoulder in the low-temperature region that is close to the HA glass transition temperature. The difference in the properties of this composite from those of the $\mathrm{CS}_{\mathrm{b}}-\mathrm{PEC}_{\mathrm{SEC}}$ is associated with the presence of weak acid salts $\left(-\mathrm{COO}^{-}\right)$in $\mathrm{HA}$ as well as the ability of HA to retain water, which, in turn, affects the chemical composition of the composite in the PEC region.

Regarding the CS/ALG polymer pair, the two-layer film demonstrates only one destruction temperature, and this differs from the destruction temperature of either of the individual components. For this polymer pair, we observed two glass transition temperatures that were close to the corresponding parameters of the initial polymers. Thus, the differences in the thermophysical and relaxation properties of the $\mathrm{CS}_{\mathrm{b}}-\mathrm{PEC}_{\mathrm{HA}}$ and $\mathrm{CS}_{\mathrm{b}}-\mathrm{PEC}_{\mathrm{ALG}}$ composites containing polyanions with carboxylate groups are associated with differences in the conformational mobility of the polyanions that form them.

Studies on the relaxation and thermal properties of multilayer composite films based on differently charged polysaccharides can provide valuable information for predicting the physicochemical properties of pervaporation membranes and multilayer composite materials for use in tissue engineering and regenerative medicine.

Author Contributions: Conceptualization, G.N.G., V.A.P., S.V.K. and Y.A.S.; methodology, G.N.G., V.A.P., S.V.K. and V.V.K.; investigation, G.N.G., V.A.P., E.N.P., V.E.S., A.N.B. and V.V.K.; writingoriginal draft preparation, G.N.G. and V.A.P.; writing-review and editing, Y.A.S.; supervision, Y.A.S. All authors have read and agreed to the published version of the manuscript.

Funding: This research received no external funding.

Institutional Review Board Statement: Not applicable.

Informed Consent Statement: Not applicable.

Data Availability Statement: The data are contained within the article.

Conflicts of Interest: The authors declare no conflict of interest.

\section{References}

1. Berger, J.; Reist, M.; Mayer, J.M.; Felt, O.; Peppas, N.A.; Gurny, R. Structure and interactions in covalently and ionically crosslinked chitosan hydrogels for biomedical applications. Eur. J. Pharm. Biopharm. 2004, 57, 19-34. [CrossRef]

2. Kulkarni, A.D.; Vanjari, Y.H.; Sancheti, K.H.; Patel, H.M.; Belgamwar, V.S.; Surana, S.J.; Pardeshi, C.V. Polyelectrolyte complexes: Mechanisms, critical experimental aspects, and applications. Artif. Cells Nanomed. Biotechnol. 2016, 44, 1615-1625. [CrossRef]

3. Luo, Y.; Wang, Q. Recent development of chitosan-based polyelectrolyte complexes with natural polysaccharides for drug delivery. Int. J. Biol. Macromol. 2014, 64, 353-367. [CrossRef] [PubMed]

4. Kononova, S.V.; Kruchinina, E.V.; Petrova, V.A.; Baklagina, Y.G.; Romashkova, K.A.; Orekhov, A.S.; Klechkovskaya, V.V. Polyelectrolyte complexes of sulfoethyl cellulose-chitosan: Effect of the structure on separation properties of multilayer membranes. Cellulose 2018, 25, 7239-7259. [CrossRef] 
5. $\quad$ Baklagina, Y.G.; Kononova, S.V.; Petrova, V.A.; Kruchinina, E.V.; Nud'ga, L.; Romanov, D.P.; Klechkovskaya, V.V.; Orekhov, A.S.; Bogomazov, A.V.; Arkhipov, S.N. Study of polyelectrolyte complexes of chitosan and sulfoethyl cellulose. Crystallogr. Rep. 2013, 58, 287-294. [CrossRef]

6. Ogawa, K.; Hirano, S.; Miyanishi, T.; Yui, T.; Watanabe, T. A new polymorph of chitosan. Macromolecules 1984, 17, 973-975. [CrossRef]

7. Petrova, V.A.; Orekhov, A.S.; Chernyakov, D.D.; Baklagina, Y.G.; Romanov, D.P.; Kononova, S.V.; Volod'ko, A.V.; Ermak, I.M.; Klechkovskaya, V.V.; Skorik, Y.A. Preparation and analysis of multilayer composites based on polyelectrolyte complexes. Crystallogr. Rep. 2016, 61, 945-953. [CrossRef]

8. Baklagina, Y.G.; Klechkovskaya, V.V.; Kononova, S.V.; Petrova, V.A.; Poshina, D.N.; Orekhov, A.S.; Skorik, Y.A. Polymorphic modifications of chitosan. Crystallogr. Rep. 2018, 63, 303-313. [CrossRef]

9. Kononova, S.V.; Kruchinina, E.V.; Petrova, V.A.; Baklagina, Y.G.; Klechkovskaya, V.V.; Orekhov, A.S.; Vlasova, E.N.; Popova, E.N.; Gubanova, G.N.; Skorik, Y.A. Pervaporation membranes of a simplex type with polyelectrolyte layers of chitosan and sodium hyaluronate. Carbohydr. Polym. 2019, 209, 10-19. [CrossRef]

10. Despond, S.; Espuche, E.; Cartier, N.; Domard, A. Hydration mechanism of polysaccharides: A comparative study. J. Polym. Sci. Part. B: Polym. Phys. 2005, 43, 48-58. [CrossRef]

11. Kim, S.J.; Shin, S.R.; Lee, S.M.; Kim, I.Y.; Kim, S.I. Thermal characteristics of polyelectrolyte complexes composed of chitosan and hyaluronic acid. J. Macromol. Sci. A 2003, 40, 807-815. [CrossRef]

12. Ostrowska-Czubenko, J.; Gierszewska-Drużyńska, M. Effect of ionic crosslinking on the water state in hydrogel chitosan membranes. Carbohydr. Polym. 2009, 77, 590-598. [CrossRef]

13. Rosca, C.; Popa, M.I.; Lisa, G.; Chitanu, G.C. Interaction of chitosan with natural or synthetic anionic polyelectrolytes. 1. The chitosan-carboxymethylcellulose complex. Carbohydr. Polym. 2005, 62, 35-41. [CrossRef]

14. Avella, M.; Di Pace, E.; Immirzi, B.; Impallomeni, G.; Malinconico, M.; Santagata, G. Addition of glycerol plasticizer to seaweeds derived alginates: Influence of microstructure on chemical-physical properties. Carbohydr. Polym. 2007, 69, 503-511. [CrossRef]

15. Kittur, F.S.; Prashanth, K.V.H.; Sankar, K.U.; Tharanathan, R.N. Characterization of chitin, chitosan and their carboxymethyl derivatives by differential scanning calorimetry. Carbohydr. Polym. 2002, 49, 185-193. [CrossRef]

16. Mati-Baouche, N.; De Baynast, H.; Vial, C.; Audonnet, F.; Sun, S.; Petit, E.; Pennec, F.; Prevot, V.; Michaud, P. Physico-chemical, thermal, and mechanical approaches for the characterization of solubilized and solid state chitosans. J. Appl. Polym. Sci. 2015, 132, 41257. [CrossRef]

17. Zhao, J.; Han, W.; Chen, H.; Tu, M.; Zeng, R.; Shi, Y.; Cha, Z.; Zhou, C. Preparation, structure and crystallinity of chitosan nano-fibers by a solid-liquid phase separation technique. Carbohydr. Polym. 2011, 83, 1541-1546. [CrossRef]

18. Landel, R.F.; Nielsen, L.E. Mechanical Properties of Polymer and Composite, 2nd ed.; CRC Press: Boca Raton, FL, USA, $1993 ;$ p. 580.

19. Petrova, V.A.; Bochek, A.M.; Lebedeva, M.F.; Gofman, I.V.; Popova, E.N.; Vlasova, E.N.; Volchek, B.Z.; Nud'ga, L.A. Chitosandextran branched copolymers: Synthesis and properties. Polym. Sci. Ser. B 2014, 56, 341-351. [CrossRef]

20. Dresvyanina, E.N.; Dobrovol'skaya, I.P.; Smirnov, V.E.; Popova, E.N.; Vlasova, E.N.; Yudin, V.E. Thermal properties of salt and base forms of chitosan. Polym. Sci. Ser. A 2018, 60, 179-183. [CrossRef]

21. Kulig, D.; Zimoch-Korzycka, A.; Król, Z.; Oziembłowski, M.; Jarmoluk, A. Effect of film-forming alginate/chitosan polyelectrolyte complex on the storage quality of pork. Molecules 2017, 22, 98. [CrossRef]

22. Kim, S.J.; Shin, S.R.; Lee, K.B.; Park, Y.D.; Kim, S.I. Synthesis and characteristics of polyelectrolyte complexes composed of chitosan and hyaluronic acid. J. Appl. Polym. Sci. 2004, 91, 2908-2913. [CrossRef]

23. Li, X.; Xie, H.; Lin, J.; Xie, W.; Ma, X. Characterization and biodegradation of chitosan-alginate polyelectrolyte complexes. Polym. Degrad. Stabil. 2009, 94, 1-6. [CrossRef]

24. Smitha, B.; Sridhar, S.; Khan, A.A. Chitosan-sodium alginate polyion complexes as fuel cell membranes. Eur. Polym. J. 2005, 41, 1859-1866. [CrossRef]

25. Kononova, S.V.; Kruchinina, E.V.; Petrova, V.A.; Baklagina, Y.G.; Romashkova, K.A.; Orekhov, A.S.; Klechkovskaya, V.V.; Skorik, Y.A. Two-ply composite membranes with separation layers from chitosan and sulfoethylcellulose on a microporous support based on poly (diphenylsulfone-n-phenylphthalimide). Molecules 2017, 22, 2227. [CrossRef]

26. Kononova, S.V.; Volod'ko, A.V.; Petrova, V.A.; Kruchinina, E.V.; Baklagina, Y.G.; Chusovitin, E.A.; Skorik, Y.A. Pervaporation multilayer membranes based on a polyelectrolyte complex of $\lambda$-carrageenan and chitosan. Carbohydr. Polym. 2018, 181, 86-92. [CrossRef]

27. Petrova, V.A.; Chernyakov, D.D.; Poshina, D.N.; Gofman, I.V.; Romanov, D.P.; Mishanin, A.I.; Golovkin, A.S.; Skorik, Y.A. Electrospun bilayer chitosan/hyaluronan material and its compatibility with mesenchymal stem cells. Materials 2019, 12, 2016. [CrossRef]

28. Petrova, V.A.; Golovkin, A.S.; Mishanin, A.I.; Romanov, D.P.; Chernyakov, D.D.; Poshina, D.N.; Skorik, Y.A. Cytocompatibility of bilayer scaffolds electrospun from chitosan/alginate-chitin nanowhiskers. Biomedicines 2020, 8, 305. [CrossRef]

29. Kennedy, G.C. Pressure-volume-temperature relations in water at elevated temperatures and pressures. Am. J. Sci. 1950, 248, 540-564. [CrossRef]

30. Saito, H.; Tabeta, R.; Ogawa, K. High-resolution solid-state carbon-13 nmr study of chitosan and its salts with acids: Conformational characterization of polymorphs and helical structures as viewed from the conformation-dependent carbon- 13 chemical shifts. Macromolecules 1987, 20, 2424-2430. [CrossRef] 
31. Okuyama, K.; Noguchi, K.; Miyazawa, T.; Yui, T.; Ogawa, K. Molecular and crystal structure of hydrated chitosan. Macromolecules 1997, 30, 5849-5855. [CrossRef]

32. Vainshtein, B.K.; Fridkin, V.M.; Indenbom, V.L. Modern Crystallography 2. Structure of Crystals; Springer: Berlin/Heidelberg, Germany, 2000; p. 521. 